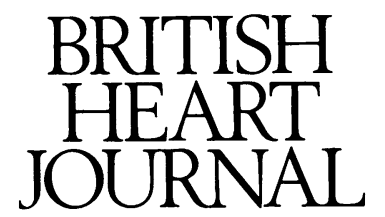

\title{
Editorial
}

\section{Patent foramen ovale in adult life}

\section{Description and prevalence}

In the fetus venous blood enters the right atrium and is directed into either the right ventricle (predominantly from the superior vena cava) or the left atrium (predominantly from the inferior vena cava, being guided by the eustachian valve across the foramen ovale). At birth the decrease in pulmonary vascular resistance and increase in systemic vascular resistance cause left atrial pressure to exceed right atrial pressure. This draws the valve of the foramen ovale against the surrounding tissue of the secundum atrial septum. The components of the septum usually adhere to seal the foramen within the first year of life but sometimes fusion is incomplete and the foramen ovale persists. ${ }^{12}$

Even if a potential channel between the atria remains, the pressure in the left atrium keeps the flap-like valve of the foramen opposed to the septum. If right atrial pressure exceeds left atrial pressure the valve can be pushed open to create a right-to-left shunt. The shunt volume depends on the pressure gradient and the size of the patent foramen ovale (PFO); both vary from moment to moment.

The prevalence of PFOs in necropsy studies was $20-35 \% .{ }^{134}$ Size is measured by finding the largest probe that fits the PFO without stretching the tissue. Formalin fixation of the samples examined may result in underestimation of the true size in vivo. In 1100 consecutive necropsies from all age groups a small probe-patent PFO was found in $29 \%$ (mean diameter $2 \mathrm{~mm}$ ) and a larger pencil-patent PFO was found in $6 \%{ }^{3}$ Half of the subjects with pencil-patent PFOs were aged less than 6 months. This suggests that a PFO of moderate size is uncommon in adults. Hagen and colleagues studied subjects from each of the first nine decades of life but excluded those aged less than one year. ${ }^{4}$ The size of the PFO ranged from $1 \mathrm{~mm}$ to $19 \mathrm{~mm}$ (mean $4.9 \mathrm{~mm}$ ) and three quarters were 1-6 $\mathrm{mm}$ in diameter. Despite the variation within each age group, the mean size of the channel was larger in older subjects. In addition, the prevalence decreased with age $34 \%$ in those aged $1-29$ years, $25 \%$ in those $30-79$ years, and $20 \%$ in those aged 80 years or more). One explanation is that the foramen ovale may seal completely after the first year of life and that the smaller the channel the more likely it is to seal.

\section{Clinical importance}

The important clinical effect of a PFO is right-to-left shunting and the consequent potential for paradoxical embolism and arterial desaturation.

PARADOXICAL THROMBOEMBOLISM

The association between PFO and stroke was first reported in $1877 . .^{5}$ Systemic embolism can occur in association with deep vein thrombosis and pulmonary embolism, if the raised right atrial pressure that follows pulmonary embolism opens the channel of the PFO. Absolute proof of paradoxical embolism was obtained only in rare cases when thrombus was found straddling a PFO. ${ }^{67}$ Until recently there were few reported cases of presumed paradoxical thromboembolism in individuals with a PFO. In 1972 only 128 cases were found in an international review of reported cases and it was generally believed that paradoxical thromboembolism is an uncommon event in individuals with a PFO. ${ }^{8}$ Though a PFO is present in about a quarter of the population and venous thrombosis is common, it was presumed that the size of the PFO does not usually allow a thrombus to pass across or else the channel is kept sealed by the prevailing differences in atrial pressures.

In 1988, however, Lechat et al compared 60 patients aged less than 55 years who were recovering from a stroke with 100 control patients who were to have posterior fossa surgery. ${ }^{9}$ They used transthoracic contrast echocardiography and the Valsalva manoeuvre. A PFO was found in $40 \%$ in the stroke patients but only $10 \%$ of the controls $(p<0.001)$. PFOs were most common in those with no other risk factor for stroke $(54 \%)$. In the same year, Webster and colleagues found a similar association between stroke and PFO in young patients, the prevalence being $50 \%$ in the stroke patients and $15 \%$ in controls $(p<0.001) . .^{10} \mathrm{~A}$ semiquantitative assessment of the shunt size was made by counting the number of microbubbles seen in the left side of the heart during frame-by-frame analysis (grade $1=1-5$; grade $2=6-20$; grade $3>20$ bubbles). The stroke patients were more likely to have grade 2 and 3 shunts than the controls.

These two studies in particular challenged the idea that paradoxical thromboembolism is uncommon in those with a PFO. The infrequency of other causes of stroke in the young made it possible to demonstrate the association in the populations studied. Since then others have used transoesophageal contrast echocardiography to show an association between PFO and stroke in older patients. ${ }^{11}$ Though the $95 \%$ confidence intervals for prevalence of PFO in the control groups in three studies ${ }^{9-11}$ overlapped, in the transoesophageal contrast echocardiographic study the prevalence in the control group was only $3 \cdot 2 \%$. This low figure may be because some of the controls had left-sided abnormalities ${ }^{12}$ (it was deemed inappropriate to perform transoesophageal echocardiography on healthy controls) and because older patients were included. The prevalence was less than that expected from necropsy data, but it may be difficult to identify a small probe-patent PFO in vivo because even 
the release of a Valsalva manoeuvre may not permit shunting. Also, when only a few microbubbles cross the atrial septum the PFO may be too small to allow paradoxical embolism and slightly larger PFOs may only become clinically significant when the arrival of an embolism in the right atrium coincides with an activity that simulates a Valsalva manoeuvre, such as heavy lifting. A large PFO can permit right-to-left shunting even under physiological conditions. ${ }^{913}$ Two further transoesophageal contrast echocardiographic studies ${ }^{14} 15$ showed a high prevalence of PFO in young patients with stroke, but another did not. ${ }^{16}$

Other abnormalities that might account for the occurrence of strokes (such as smoking, use of oral contraceptives, hypertension, mitral valve prolapse, atrial septal aneurysm, evidence of cerebrovascular disease) are also common in both young and old patients. ${ }^{113}$ Even though it can be impossible to demonstrate evidence of the deep vein thrombosis that could be the source of emboli in those without other risk factors, ${ }^{15} 17$ the weight of evidence favours the association between PFO and stroke, particularly in the young.

\section{OTHER PARADOXICAL EMBOLI}

PFOs that permit paradoxical embolism of thrombus will presumably also allow shunting of other emboli such as tumour, lipid, infected material, and gas. Septic embolism is a cause of cerebral abscess in patients with congenital heart defects and right-to-left shunts, but there is no report of an association between PFO and cerebral abscess.

PFOs are a well recognised cause of paradoxical gas embolism during some interventions, particularly neurosurgery. ${ }^{18}$ Indeed, before some procedures preoperative screening may be advisable to detect PFOs, and those who have a PFO may require intraoperative monitoring for evidence of paradoxical air embolism. ${ }^{19}$

\section{DECOMPRESSION SICKNESS}

Paradoxical gas embolism via a PFO also seems to be responsible for some types of decompression sickness, particularly when symptoms occur after relatively innocuous dives..$^{21}$ In one study transthoracic contrast echocardiography showed a PFO in $41 \%$ of subaqua divers who had symptoms of decompression sickness but only $24 \%$ of matched control divers who did not. ${ }^{20}$ The prevalence was highest $(66 \%)$ in those who had neurological symptoms within 30 minutes of surfacing. In another study of 30 divers with decompression sickness the results were similar. There was an overall PFO prevalence of $37 \%$ but it was $61 \%$ for the 18 patients with serious symptoms and signs. ${ }^{21}$ PFOs also seem to predispose to cardiorespiratory and cutaneous decompression sickness but not limb (joint) decompression sickness. ${ }^{22}$

\section{ARTERIAL DESATURATION}

Pulmonary thromboembolism increases right heart pressures. In those with a PFO this may permit right-to-left shunting of venous blood, which will exacerbate the effects of pulmonary shunting and worsen arterial hypoxemia. ${ }^{23}$ However, pulmonary hypertension is not a prerequisite for right-to-left shunting and arterial desaturation. Shunting can occur after resection of lung tissue. ${ }^{24-26}$ It has been proposed that a change in anatomical relations between the inferior vena cava and the atrial septum is responsible, but arterial desaturation caused by shunting across a PFO can occur in individuals with normal cardiac pressures and no lung disease. ${ }^{25}$ Arterial saturation can change with posture, with a tendency for dyspnoea and desaturation to develop in the upright position (platypnoea-orthodeoxia). ${ }^{25}$ Shunting via a PFO should always be considered in patients with unexplained cyanosis and in the most severe cases may require closure of the PFO.

\section{Methods of detection}

Visual inspection at surgery or necropsy is the only definitive means of diagnosing a PFO. There are also several clinical diagnostic tests. A PFO may be found during right heart catheterisation if the catheter passes into the left atrium. In those in whom desaturation is believed to be caused by shunting across a PFO return of arterial saturations to normal when the balloon at the catheter tip is inflated and pulled back against the atrial septum confirms the site of the shunt. ${ }^{27}$ This will not distinguish between a PFO and a small secundum atrial septal defect. However, atrial angiograms that show the interatrial septum in profile will often identify the lesion. A left atrial angiogram should show no contrast passing into the right atrium unless there is a stretched PFO, and a right atrial angiogram may show movement of the flap of the PFO. ${ }^{25}$

Indicator dilution curves can show the presence of a right-to-left shunt but not its nature, though localisation to the atrial level is possible if injections are made proximal and distal to the site of the shunt. ${ }^{8}$ This invasive procedure, however, cannot exclude a PFO. Magnetic resonance imaging has been used to assess atrial septal defects $^{28}$ but its value in the detection of a PFO is unknown.

The best imaging method for PFOs is contrast echocardiography. It is usually necessary to perform several studies, but sensitivity is increased when contrast studies are combined with a cough or Valsalva or equivalent manoeuvres, and increased further by transoesophageal contrast and colour-flow map studies. ${ }^{29-31}$ In certain clinical situations, transoesophageal echocardiography has the potential advantage of showing proximal pulmonary artery thrombus. ${ }^{32} 33$ The transoesophageal technique provides high definition images of the valve of the foramen ovale and the surrounding septal tissue and can help to distinguish between a PFO and an atrial septal defect. This can be difficult when there is important left heart pathology because a widely patent PFO caused by stretching of the valve may be impossible to distinguish from a septal defect. ${ }^{12}$ Under these circumstances, however, paradoxical events are less likely because leftto-right shunting dominates.

Shunts can also be detected by transcranial Doppler examination of the middle cerebral artery during peripheral venous injection of contrast, but the technique does not distinguish between cardiac and pulmonary shunts. ${ }^{34}$

\section{Quantification of the shunt}

There is no proven method of quantifying the shunt across a PFO. There are many difficulties in this. With a stretched PFO and left-to-right shunting oximetric methods can be applied, as with atrial septal defects. However, quantification in the usual clinical setting of right-to-left shunting is usually impossible, not least because shunting is intermittent. The bubble counting method ${ }^{10}$ is only semi-quantitative and has not been validated. The variability of the technique with and without provocative manoeuvres is not known. Other techniques have not been fully evaluated. Pulse oximetry provides a method of evaluating desaturation, but this may prove useful only in patients with the largest right-to-left shunts. 


\section{Treatment}

For patients who have had a stroke there are no agreed methods of management. The natural history of stroke in association with a PFO is unknown and therefore the influence of treatment is uncertain. There are several options, all of which have been tried in individual patients. These include doing nothing, prescribing aspirin or warfarin, insertion of inferior vena cava filters, and closure of the PFO. Until more information is available each case requires individual management.

Thus anticoagulation is appropriate for patients with definite paradoxical embolism and deep vein thrombosis and pulmonary embolism, but the duration depends on the clinical situation. An inferior vena cava filter or ligation or closure of the PFO can be used, especially if the patient has had recurrent events while being treated with anticoagulants. It is more difficult to decide the most appropriate treatment when a stroke occurs in a patient without evidence of venous thrombosis. Even in young patients with a PFO and no other identifiable cause of stroke it is not possible to be certain that paradoxical embolism was responsible. We recommend treatment with oral anticoagulants but also discuss the option of closure of the PFO. Closure is appropriate if the events recur and there are relative contraindications to anticoagulants or if the patient prefers closure to lifelong treatment with anticoagulants. Until recently this meant surgical closure, but percutaneous closure with a double umbrella or clam-shell device is now feasible in some individuals, ${ }^{35}$ depending on the size and anatomy of the PFO ${ }^{36}$ So far the results with such devices suggest that they are an attractive option because the closure procedure is less invasive. Where deep vein thrombosis is present care must be taken to avoid dislodging more thrombus. Multicentre studies should be set up to compare the results of these therapeutic options.

Patients with significant desaturation may need closure of the PFO. Percutaneous closure seems particularly attractive in patients who have desaturation as a complication of lung resection, because the risk of open heart surgery is high. Temporary closure with a balloon-tipped catheter is sometimes valuable when right-to-left shunting complicates acute haemodynamic events, such as myocardial infarction. ${ }^{37}$ Divers who want to continue their sport without restriction may prefer closure too.

\section{Implications and recommendations for diving and other activities}

Should all patients with non-haemorrhagic stroke have a transoesophageal contrast echocardiogram? There are many reasons why the answer should be no. If the computed tomogram shows a lacunar infarct, embolism is unlikely to be the cause. Many patients with stroke are older and have readily identifiable causes such as valve disease or atrial fibrillation. Management may not be influenced by finding a PFO. However, we believe that young patients with no identifiable cause of stroke should be investigated, and if a PFO is found (particularly if there is a grade 2 or 3 shunt on contrast studies) the therapeutic options should be discussed. The role of venography in such patients needs further evaluation, particularly because the procedure can dislodge thrombus and initiate new thrombus formation.

Certainly all patients with unexplained breathlessness and cyanosis or oximetric evidence of desaturation (even when this is intermittent) should be investigated by contrast echocardiography with a view to closure.

Lastly, should all subaqua divers be screened for a PFO? This is impractical. There are over 50 thousand scuba divers in the United Kingdom and over a quarter of a million in the United States. Decompression sickness is rare (about 100 cases annually in the United Kingdom) in terms of the population at risk. Some divers with a PFO never suffer decompression sickness and it would be unreasonable to prevent them diving. There are other aetiological factors in decompression sickness, such as the dive profile and the size of the shunt. Until we can determine precisely which individuals with a PFO are at risk, we can only test those who have decompression sickness for the presence of a PFO. If a PFO (or other right-to-left shunt) is found this does not necessarily mean closure or a ban on all future diving. It seems that in such cases only certain dive profiles will precipitate decompression sickness. Perhaps the best hope of reducing decompression sickness is to ask all divers to avoid the high risk profiles.

Huddersfield Royal Infirmary, Lindley, Huddersfield, Yorkshire HD3 $3 E A$

South Cleveland Hospital, Marton Road, Middlesborough, Cleveland TS4 3BW

1 Schroekenstein RF, Wasenda GJ, Edwards JE. Valvar competent patent foramen ovale in adults. Minn Med 1972;55:11-3.

2 Hurst JW. Fetal circulation and changes associated with birth. In: Hurst JW, ed. The heart. New York: McGraw Hill, 1978:813-30.

3 Thompson T, Evans W. Paradoxical embolism. Q f Med 1930;23: 135-50.

4 Hagen PT, Scholz DG, Edwards WD. Incidence and size of patent foramen ovale during the first 10 decades of life; an autopsy study of 965 normal hearts. Mayo Clin Proc 1984;59:17-20.

5 Cohnheim J. Thrombose und embolie. Vorlesungen Uber Allgemeine Pathologie. Vol 1. Berlin: Hirschwald, 1877:134.

6 Nagelhout DA, Pearson AC, Labovitz AJ. Diagnosis of paradoxical embolism by transesophageal echocardiography. Am Heart $\mathcal{f}$ 1991;121: 1552-4.

7 Nelson CW, Snow FR, Barnett M, McRoy L, Wechsler AS, Nixon JV. Impending paradoxical embolism: echocardiographic diagnosis of an intracardiac throm

8 Meister SG, Grossman W, Dexter L, Dalen JE. Paradoxical embolism. Diagnosis during life. Am $\mathcal{F}$ Med 1972;53:292-8.

9 Lechat PH, Mas JL, Lascault G, Loron PH, Theard M, Klimczac M, et al. Prevalence of patent foramen ovale in patients with stroke. $N$ Engl $\mathcal{F}$ Med 1988;318:1144-52.

10 Webster MWI, Chancellor AM, Smith HJ, Swift DL, Sharpe DN, Bass NM, et al. Patent foramen ovale in young stroke patients. Lancet 1988;ii: $11-2$.

11 de Belder MA, Tourikis L, Leech G, Camm AJ. Risk of patent foramen ovale for thromboembolic events in all age groups. Am $\mathcal{f}$ Cardiol 1992;69:1316-20.

12 Siostrzonek $P$, Lang $W$, Zangeneh $M$, Gossinger $H$, Stumpflen A, Rosenmayr G, et al. Significance of left-sided heart disease for the detection of patent foramen ovale by transesophageal echocardiography. 7 Am Coll Cardiol 1992;19:1192-6.

13 Lynch J, Schuchard GH, Gross CM, Wann LS. Prevalence of right-toleft atrial shunting in a healthy population: detection by Valsalva maneuver contrast echocardiography. Am $\mathcal{f}$ Cardiol 1984;53:1478-80.

14 Hausmann D, Mugge A, Becht I, Daniel WG. Diagnosis of patent foramen ovale by transesophageal echocardiography and association with cerebral and peripheral embolic events. Am f Cardiol 1992;70:668-72.

15 Ranoux D, Cohen A, Cabanes L, Amarenco P, Bousser MG, Mas JL Patent foramen ovale: is stroke due to paradoxical embolism? Stroke 1993;24:31-4.

16 Brickner ME, Friedman DB, Cigarroa CG, Peters A, Abraham M, Lacker $M$, et al. Patent foramen ovale in young patients with stroke or transient ischaemic attack is an incidental finding by transesophageal echocardioischaemic attack is an incidental finding by tran

17 Gautier JC, Durr A, Koussa S, Lascault G, Grosgogeat Y. Paradoxical cerebral embolism with a patent foramen ovale. Cerebrovasc Dis 1991;1:193-202.

18 Gronert GA, Messick JM, Cucchiara RF, Michenfelder JD. Paradoxical air embolism from a patent foramen ovale. Anesthesiology 1979;50: 548-9.

19 Black S, Muzzi DA, Nishimura RA, Cucchiara RF. Preoperative and intraoperative echocardiography to detect right-to-left shunts in patients undergoing neurosurgical procedures in the sitting position. Anesthesiology 1990;72:436-8.

20 Wilmshurst PT, Byrne JC, Webb-Peploe MM. Relation between interatrial shunts and decompression sickness in divers. Lancet 1989;ii: 1302-5.

21 Moon RE, Camporesi EM, Kisslo JA. Patent foramen ovale and decompression sickness in divers. Lancet 1989;i:513-4.

22 Wilmshurst PT, Byrne JC, Webb-Peploe MM. Relation between interatrial shunts and decompression sickness in divers. In: Sterk W, trial shunts and decompression sickness in divers. In: Sterk W, Geeraedts L, eds. EUBS 1990 Proceedin

23 Kasper W, Geibel A, Tiede N, Just H. Patent foramen ovale in patients with haemodynamically significant pulmonary embolism. Lancet 1992; 340:561-4. 
24 Vacek JL, Foster J, Quinton RR, Savage PJ. Right to left shunting after lobectomy through a patent foramen ovale. Ann Thorac Surg 1985;39: 576-8.

25 Seward JB, Hayes DL, Smith HC, Williams DE, Rosenow EC, Redder GS, et al. Platypnea-orthodeoxia: Clinical profile, diagnostic workup, management, and report of seven cases. Mayo Clin Proc 1984;59: 221-31.

26 Remy-Jardin M, Remy J, Wallaert B. Right-to-left shunting through a patent foramen ovale without pulmonary hypertension. Transient
improvement after balloon catheter closure. Chest 1990;97:1250-2.

27 Lemaire F, Richalet JP, Carlet J, Brun-Buinan C, MacLean C. Post-operative hyoxemia due to opening of a patent foramen ovale confirmed by a right atrium-left atrium pressure gradient during mechanical ventilation. right atrium-left atrium pressure
Anesthesiology 1982;5:233-6.

28 Diethelm L, Dery R, Lipton MJ, Higgins CB. Atrial level shunts: sensitivity and specificity of MR in diagnosis. Radiology 1987;162:181-6.

29 Valdes-Cruz LM, Pieroni DR, Roland JM, Varghes PJ. Echocardiographic detection of intracardiac right-to-left shunts following peripheral vein injection. Circulation 1976;54:558-62.

30 Mugge A, Daniel WG, Klopper JW, Lichtlen PR. Visualisation of patent foramen ovale by transesophageal color-coded Doppler echocardiography. Am $\mathcal{F}$ Cardiol 1988,62:837-8.

31 de Belder MA, Tourikis L, Griffith M, Leech G, Camm AJ.
Transesophageal contrast echocardiography and color flow mappingmethods of choice for the detection of shunts at atrial level? Am Heart $\mathcal{F}$ 1992;124:1545-50

32 Marber MS, de Belder MA, Pumphrey CW, Leech G, Camm AJ. Transoesophageal echocardiography in the diagnosis of paradoxical embolism. Int $\mathcal{f}$ Cardiol 1992;34:283-8.

33 Nixdorff U, Erbel R, Drexler M, Mayer J. Detection of thrombo-embolus of the right pulmonary artery by transoesophageal two dimensional echocardiography. Am $₹$ Cardiol 1988;61:448-9.

34 Nemec J, Marwick TH, Loring RJ, Davidson MB, Chimowitz MI, Litowitz $\mathrm{H}$, et al. Comparison of transcranial doppler ultrasound and transesophageal contrast echocardiography in the detection of interatrial right-to-left shunts. Am $\mathcal{F}$ Cardiol 1991;68:1498-502.

35 Bridges ND, Hellenbrand W, Latson L, Filiano J, Newburger JW, Lock $\mathrm{JE}$. Transcatheter closure of patent foramen ovale after presumed paradoxical embolism. Circulation 1992;86:1902-8.

36 Ferreira SMAG, Ho SY, Anderson RH. Morphological study of defects of the atrial septum within the oval fossa: implications for transcatheter closure of left-to-right shunt. Br Heart $\mathcal{F}$ 1992;67:316-20.

37 Gudipati CV, Nagelhout DA, Serota H, Deligonul U, Labovitz AJ, Kern MJ. Transesophageal echocardiographic guidance for balloon catheter occlusion of patent foramen ovale complicating right ventricular infarction. Am Heart $f$ 1991;121:919-22.

\section{Indexing the British Heart fournal: choice of keywords}

From 1994 there will be a change in the method of indexing subjects in the British Heart fournal. In addition the author index will no longer include the title of the paper and will become a list of authors only. Papers and proceedings will be indexed by a keyword system, and authors of papers and proceedings will be asked to choose up to three keywords for each paper at manuscript stage, which will then contribute to the compilation of an annual index. A keyword is a word (or phrase) which will identify the subject matter of a written paper or proceeding in an index. The index will be published, as usual, at the end of each volume, in the June and December issues. The format will be different, with the title of the paper repeated after each keyword on every entry.

On the surface, choosing index headings does not appear to be difficult. Medicine, however, because of its synonyms, phrasal headings, proprietary and pharmaceutical names of drugs, syndromes, latin words, and assorted lay terms produces problems of its own. Examples include whether to use cardiac or heart failure; pulmonary or lung; ventricle, left, or left ventricle; angina, Prinzmetal or Prinzmetal angina; and problems with ischaemic heart disease, myocardial ischaemia, and related diseases abound.

An index should be constant. It is not good if half the entries are under Left ventricle and the other under Ventricle, left, and whereas it is reasonable to make some decisions about the entries that can be anticipated, authors will not know what other work is being published, or under what titles, in the same volume. The keyword will be chosen at the earliest stage of publication not at the latest as it is now, and as each article will be dealt with in isolation there will be no links between articles of like subject matter.

Authors are advised to scan their papers for headings that may not be in the title, to use British approved names rather than pharmaceutical names for drugs, and to avoid general terms such as clinical, complications, adverse effects, and patient. As the subject of the journal is "Heart" it is better not to use this as a heading, with a few exceptions such as Heart transplantation, Heart failure, Heart rate. In general, it is better not to split accepted concepts. For instance, Atrial septal defect is preferable as a keyword, rather than Defect, atrial septal.

Some shortened forms can be accepted. DNA, AIDS, HIV, and cAMP are universally known and are the terms that will spring to the mind of a reader using the index. But generally the full form should be used as the keyword. Alphafetoprotein and Alpha and Beta receptor blockade are the usual terms and gamma-aminobutyric acid is indexed under GABA, but the Greek letter is generally not used in alphabetisation. Put all Ventricular entries under Ventricle, and use Heart failure rather than Cardiac failure, Aortic arch rather than Arch, aortic, but Cardiomyopathies under the specific type. There will be no cross references in the keyword index.

This cannot be more than an attempt to guide authors and perhaps to warn of the pitfalls, but it is important to remember that if authors wish to have their work found easily in the index they should consider the keywords carefully.

DOREEN BLAKE Indexer BMf Publishing Group 